\title{
Effects of remote ischemic post-conditioning on fracture healing in rats
}

\author{
MENG ZHOU ${ }^{1}$, SHIBAO LU ${ }^{1}$, GUOWEI LU ${ }^{2}$, JIANG HUANG ${ }^{1}$, \\ LIMIN LIU $^{1}$, SHUAI AN ${ }^{1}$, ZHENG LI $^{1}$ and HUILIANG SHEN ${ }^{1}$ \\ ${ }^{1}$ Department of Orthopedics; ${ }^{2}$ Institute of Hypoxia Medicine, \\ Xuanwu Hospital, Capital Medical University, Beijing 100053, P.R. China
}

Received December 19, 2015; Accepted January 1, 2017

DOI: $10.3892 / \mathrm{mmr} .2017 .6348$

\begin{abstract}
Remote ischemic post-conditioning (RIPC) is an established method to activate the hypoxia-inducible factor- $1 \alpha(\mathrm{HIF}-1 \alpha)$ pathway, which is involved in the impairment of fracture healing. However, the role of RIPC in fracture healing remains to be fully elucidated. In the present study, rats received fractures and were divided into two groups: Control and RIPC, in which hind limb occlusion was performed. Rats were sacrificed at 7,14, 28 and 42 days subsequent to tibial fracture. Micro-computed tomography was performed to measure healing of the bone tissue and biomechanical testing was used to test mechanical strength. In addition, the effects of hind limb occlusion on the expression of two primary angiogenic mediators, HIF-1 $\alpha$ and vascular endothelial growth factor (VEGF), as well as the osteoblast markers runt-related transcription factor 2 (Runx2), alkaline phosphatase (ALP) and osteocalcin $(\mathrm{OCN})$, were determined at the mRNA and protein levels by reverse transcription-quantitative polymerase chain reaction, western blot analysis and immunohistochemistry. Systemic administration of hind limb occlusion (3 cycles/day, with each occlusion or release phase lasting $10 \mathrm{~min}$ ) significantly promoted fracture healing and mechanical strength. The present study demonstrated that in rats treated with hind limb occlusion, the expression of HIF-1 $\alpha$, VEGF, Runx2, ALP and OCN was significantly increased at the mRNA and protein levels, and that RIPC enhances fracture repair in vivo.
\end{abstract}

\section{Introduction}

Traumatic fracture is one of the most common injuries in daily life. In clinical cases, numerous methods are used to decrease injury, and the majority of simple fractures heal with minimal

Correspondence to: Dr Huiliang Shen, Department of Orthopedics, Xuanwu Hospital, Capital Medical University, 45 Changchun Street, Beijing 100053, P.R. China

E-mail: shenhuiliang2015@163.com

Key words: remote ischemic post-conditioning, fracture, hypoxia, hypoxia-inducible factor- $1 \alpha$, vascular endothelial growth factor intervention; however, in certain complex cases, including fractures in diabetics and splintered fractures, there may be impaired fracture healing and bone defects (1,2). Although advances have been made, certain patients with independent factors (fracture pattern, location, displacement, severity of soft tissue injury, degree of bone loss, quality of surgical treatment and presence or absence of infection) (3) require prolonged reconstructive procedures and still experience nonunion (2).

The hypoxia-inducible factor-1 $\alpha$ (HIF) pathway is the central pathway for sensing and responding to alterations in the local oxygen tension in a wide variety of organisms (4). Activation of the HIF-1 $\alpha$ pathway is a critical mediator of the neoangiogenesis required for skeletal regeneration, suggesting the application of HIF activators as therapies for improving bone healing (4). Increasing data suggests that hypoxia may be considered a powerful stimulus for bone cells by influencing angiogenesis via the vascular endothelial growth factor (VEGF), cellular metabolism via the glucose transporter and recruiting mesenchymal stem cells (MSCs) to areas of matrix damage (5-7). A more thorough understanding of hypoxia in bone healing may identify novel underlying cellular and molecular mechanisms that may offer potential protective effects. In our previous study, $\mathrm{CoCl}_{2}$ was demonstrated to enhance fracture healing by inducing bone and cartilage formation and increasing tissue vascularization; furthermore, $\mathrm{CoCl}_{2}$ may activate the HIF-1 $\alpha$ pathway (8). However, $\mathrm{CoCl}_{2}$ has certain toxic effects on specific hematological factors (9). Therefore, the aim of the present study is to identify a non-toxic alternative.

Bone ischemia-reperfusion occurs during various clinical procedures, including orthopedic arthroplasty, plastic gnathoplasty, spinal surgery and amputation. Fracture of bone reduces or disrupts the tissue blood supply; during fracture healing, neovascularization and vascular growth take place. This is hypothesized to constitute reperfusion of an ischemic region and the production of oxygen free radicals (10). Simulation of this hypoxia-reoxygenation physiological process may further elucidate understanding of the underlying mechanism.

The protective effect of ischemia/hypoxia pre-conditioning (IPC) has been demonstrated by numerous experimental and clinical studies. Studies have revealed that IPC may enhance the expression of HIF-1 and VEGF $(11,12)$. However, the use of this technique is limited, as treatment must occur 
prior to ischemia. A modification of this technique involves brief coronary artery occlusions and reperfusions performed at myocardial reperfusion, ischemic post-conditioning (13). In 2003, Zhao et al (14) first demonstrated reproducible experimental results following this procedure. However, remote conditioning was first described by Przyklenk et al (15) in 1993. Remote ischemic post-conditioning (RIPC) $(16,17)$ was developed as a protective strategy similar to local post-conditioning. HIF-1 $\alpha$ and VEGF expression are increased in the ischemic muscle of animals following hind-limb ischemia (18).

The present study hypothesized that RIPC results in accelerated fracture healing. To determine whether systemic application of RIPC enhances rates of fracture healing in a pre-clinical model, the effects of RIPC on callus formation, fracture healing, callus mechanical strength and integrity and gene expression in vivo were investigated.

\section{Materials and methods}

Animal care. All animal experiments were approved by the Animal Care and Use Committee of Xuanwu Hospital, Capital Medical University (Beijing, China), and were conducted according to guidelines produced by the National Institutes of Health (Bethesda, MD, USA). A total of 64 adult male Sprague-Dawley (SD) rats (age, 6 weeks; weight, 185-220 g) were purchased from the Laboratory Animal Center of Capital Medical University. The animals were housed in groups of 4 in the same animal care facility throughout the duration of the study and were maintained at a temperature of $23-25^{\circ} \mathrm{C}$ and a humidity of 50-60\%, under a 12-h light/dark cycle, and with unlimited access to food and water. All efforts were made to minimize any suffering and to reduce the total number of animals used.

Animal experiments. Animals were acclimatized to the conditions for 1 week prior to experiments. Surgery was performed with a fracture device, as described previously (19). Prior to the procedure, the animals were anesthetized by an intraperitoneal injection of $1 \%$ sodium pentobarbital $(4 \mathrm{mg} / \mathrm{kg}$ body weight). Fractures were created at the tuberositas tibiae using a blunt guillotine driven by a drop weight; a wire driver was used to insert a steel K-wire into the medullary canal. Radiographs were performed immediately to confirm the extent of fractures. At 7, 14, 28 and 42 days following fracture ( $n=8$ /group at each time point), radiographs were obtained, and the rats were sacrificed by cervical dislocation. The K-wire was removed, the tibiae were dissected and the fracture zone was prepared for reverse transcription-quantitative polymerase chain reaction (RT-qPCR), western blotting, immunohistochemistry (IHC), micro-computed tomography (micro-CT) and biomechanical testing.

RIPC. A total of 64 male SD rats were assigned to two groups: Control $(n=32)$ and RIPC $(n=32)$. RIPC was initiated immediately following the K-wire operation by occluding blood flow to the other hind limb. Hind limb occlusion was performed by tightening a tourniquet $(18-\mathrm{mm})$ around the upper thigh and releasing in for 3 cycles, with each occlusion or release phase lasting $10 \mathrm{~min}$, this was performed once a day over 7 days (20). This method has been previously demonstrated to completely occlude the blood, as assessed using the vascular assessments system (Periflux System 5000; Perimed AB, Järfälla, Sweden; Fig. 1). The control group received the same dosage of sodium pentobarbital.

Micro-CT analysis. The tibia was scanned using an Inveon Micro-CT (Siemens AG, Munich, Germany). The scan protocol was as follows: $15 \mu \mathrm{m}$ specimen, $500 \mu \mathrm{a}, 80 \mathrm{kv}$. A $3 \mathrm{D}$ reconstruction was performed using Mimics software version 16.0 (Materialise NV, Leuven, Belgium). The 3D measurement area extended $2.5 \mathrm{~mm}$ proximally and distally from the osteotomy line (21). The thresholds were defined by averaging the values determined visually by the analyses of the software ( $n=3$ per group). Callus volumes and gray values were quantified.Micro-CT scans at multiple time points post-fracture (14, 28 and 42 days) were assessed blindly by three independent investigators (22).

$R N A$ extraction and $R T-q P C R$. Total RNA was extracted from fresh bone tissues of each group using TRIzol ${ }^{\circledR}$ reagent according to the manufacturer's protocol (Invitrogen; Thermo Fisher Scientific, Inc., Waltham, MA, USA). The RNA quantity and quality were determined using a NanoDrop 2000 spectrophotometer (Thermo Fisher Scientific, Inc., Wilmington, DE, USA). Total RNA (500 ng) was reverse transcribed using the ReverTra Ace ${ }^{\circledR}$ (Toyobo Co., Ltd., Osaka, Japan) according to the manufacturer's instructions. qPCR was performed to measure the mRNA expression levels relative to $\beta$-actin (ACTB), using an iCycle iQ Real-Time PCR Detection system (Bio-Rad Laboratories, Inc., Hercules, CA, USA) and SYBR-Green ${ }^{\circledR}$ Master mix (Toyobo Co., Ltd.). The primers used were as follows: Forward, 5'-CCCCTACTATGTCGC TTTCTTGG-3' and reverse, 5'-GGTTTCTGCTGCCTTGTA TGG-3' for HIF-1 $\alpha$; forward, 5'-CGACAAGGCAGACTA TTCAACG-3' and reverse, 5'-GGCACGATTTAAGAGGGG AAT-3' for VEGF; forward, 5'-CCCACGAATGCACTATCC AG-3' and reverse, 5'-GGCTTCCATCAGCGTCAACA-3' for Runx2; forward, 5'-GGACGGTGAACGGGAGAAC-3' and reverse, 5'-CCCTCAGAACAGGGTGCGTAG-3' for ALP; forward, 5'-CGGACCACATTGGCTTCCAG-3' and reverse, 5'-GCTGTGCCGTCCATACTTTCG-3' for OCN; and forward, 5'-CCGTAAAGACCTCTATGCCAACA-3' and reverse, 5'-CGGACTCATCGTACTCCTGCT-3' for ACTB; forward, 5'-GGCAAGTTCAACGGCACAG-3' and reverse, 5'-CGCCAGTAGACTCCACGACA-3'. The thermocycling conditions were as follows: An initial predenaturation step at $95^{\circ} \mathrm{C}$ for $2 \mathrm{~min}$, followed by 40 cycles of denaturation at $95^{\circ} \mathrm{C}$ for $10 \mathrm{sec}$ and annealing at $60^{\circ} \mathrm{C}$ for $30 \mathrm{sec}$. The expression values were normalized against GAPDH (23) using the $2^{-\Delta \Delta C q}$ method (24). All experiments were performed in triplicate and were repeated at least three times.

IHC analysis. Sections were prepared and processed using standard techniques following a previously described method (25). Briefly, tissues generated from callus were cut into $3 \mu \mathrm{m}$ and mounted on slides. Following deparaffinization and hydration, antigen retrieval was performed using $0.05 \%$ trypsin, and sections were incubated with $3 \% \mathrm{H}_{2} \mathrm{O}_{2}$ in methanol for $10 \mathrm{~min}$ to inhibit endogenous peroxide. Subsequently, slides were incubated with primary antibodies in blocking solution 


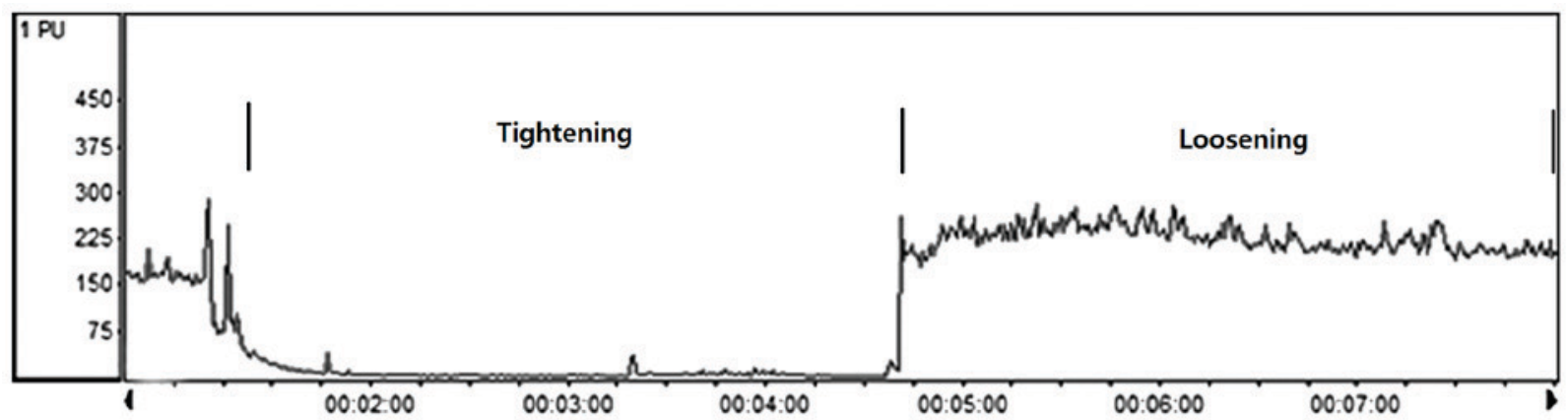

Figure 1. Rheography of an occluded hind limb during tightening and loosening of the tourniquet.

(10\% goat serum; Thermo Fisher Scientific, Inc.) in a humidified chamber at $4^{\circ} \mathrm{C}$ overnight. The following primary antibodies were used: Mouse anti-Runx2 (1:200; cat. no. ab76956; Abcam, Cambridge, UK), rabbit anti-ALP (1:300; cat. no. ab95462; Abcam) and mouse anti-OCN (1:200; cat. no. ab13420; Abcam). Following this, sections were incubated with the biotinylated goat anti-mouse (cat. no. ab6788; dilution 1:250; Abcam) and goat anti-rabbit IgG (cat. no. ab6720, dilution 1:100; Abcam) for $10 \mathrm{~min}$ at $37^{\circ} \mathrm{C}$. Following washing with PBS, the sections were incubated with streptavidin-peroxidase conjugate (Rockland Immunochemicals Inc. Limerick, PA, USA) for $10 \mathrm{~min}$. Color was developed using diaminobenzidine tetrahydrochloride solution (Ventana Medical Systems, Inc., Tucson, AZ, USA). Sections were counterstained with hematoxylin, dehydrated and mounted. Negative controls included replacement of the primary antibody with PBS of the same concentration.

Scoring was performed by two independent observers who had no knowledge of the rat outcome or corresponding pathological parameters. The percentage of stained cells and staining intensity were scored. Staining intensity was scored as follows: 0 , no staining; 1 , weak intensity; 2 , moderate intensity; and 3, high intensity. The number of positive cells was evaluated as follows: 0 (negative), $<10 \%$ positive cells; 1 (weak), $<30 \%$ positive cells; 2 (moderate), $<50 \%$ positive cells; and 3 (strong), $>70 \%$ positive cells.

Biomechanical testing. Hydrated tibias were tested in torsion using previously published methods (26). The rat tibias from each group were assessed to failure by three-point bending using a material testing system (ELF 3400; Enduratec Systems Group; Bose Corporation, Framingham, MA, USA). Biomechanical parameters including breaking force (maximum load), stiffness (average slope of linear portion of the curve before yielding) and work-to-fracture (bend strain at maximum and bend strength at maximum) were calculated from the force displacement data.

Western blot analysis. Western blot analysis was used to assess HIF-1 $\alpha$, VEGF, ALP, Runx 2 and OCN protein expression levels. Protein was isolated from the rat callus region at 7, 14, 28 and 48 days following fracture. Radioimmunoprecipitation assay buffer containing protease inhibitors (Sigma-Aldrich; Merck Millipore, Darmstadt, Germany) was used to prepare tissue lysates with $1 \%$ SDS. The total proteins $(50 \mu \mathrm{g})$ were resolved on a $10 \%$ SDS-PAGE gels and transferred onto polyvinylidene difluoride membranes (Sigma-Aldrich; Merck Millipore). The membranes were blocked in 5\% skim milk in TBS containing $0.1 \%$ Tween-20 (TBST) for $1 \mathrm{~h}$ and incubated overnight at $4^{\circ} \mathrm{C}$ with the following primary antibodies: Mouse anti-HIF-1 $\alpha$ (cat. no. ab463; Abcam), rabbit anti-VEGF (cat. no. ab46154; Abcam), rabbit anti-ALP (cat. no. ab95462; Abcam), mouse anti-Runx2 (cat. no. ab76956; Abcam), mouse anti-OCN (cat. no. ab13420; Abcam) and actin (cat. no. sc-47778; Santa Cruz Biotechnology, Inc., Dallas, TX, USA). All antibodies were diluted 1:1,000 in Tris-buffered saline. The blots were washed in TBST and then incubated for $1 \mathrm{~h}$ with anti-goat horseradish peroxidase-conjugated immunoglobulin $\mathrm{G}$ (IgG) $(1: 2,000$; cat. nos. ZB-2305 and ZB-2301; OriGene Technologies, Inc., Beijing, China) at $37^{\circ} \mathrm{C}$. Bands and band intensity were detected using Super ECL Plus kit (cat. no. P1010; Applygen Technologies, Inc., Beijing, China). $\beta$-actin served to verify equal loading.

Statistical analysis. Data are expressed as the mean \pm standard deviation, and statistical analyses were performed with SPSS software, version 19.0 (IBM SPSS, Armonk, NY, USA). For comparisons between the two groups, Student's t-test was performed. In all cases, $\mathrm{P}<0.05$ was considered to indicate a statistically significant difference.

\section{Results}

Micro CT scans of the interfragmentary zone. After 14 and 28 days of fracture, a significant increase in the callus volume of specimens was detected in the group that underwent RIPC treatment compared with the control animals $(\mathrm{P}<0.01$; Figs. 2 and 3). Following 42 days, the opposite trend was observed $(\mathrm{P}<0.01)$. To quantify the formation of the callus, the gray value generated by micro $\mathrm{CT}$ scans within the defined area was analyzed. After $14(\mathrm{P}<0.01), 28(\mathrm{P}<0.05)$ and 42 $(\mathrm{P}<0.01)$ days, a significant increase of the gray value was detected in the RIPC compared with the control group (Fig. 4).

Protein and mRNA expression levels of angiogenic mediators and osteoblast markers. Protein (Fig. 5) and mRNA (Fig. 6) expression levels of HIF-1 $\alpha$ were increased in RIPC compared with control groups at all time points $(\mathrm{P}<0.01)$. To further evaluate if HIF-1 $\alpha$ had a direct functional role in this process, the expression of downstream genes of HIF-1 $\alpha$ were investigated. The results of the present study demonstrated that RIPC increased VEGF, Runx2, ALP and OCN protein (Fig. 5) and mRNA (Fig. 6) expression. These results suggested that the 


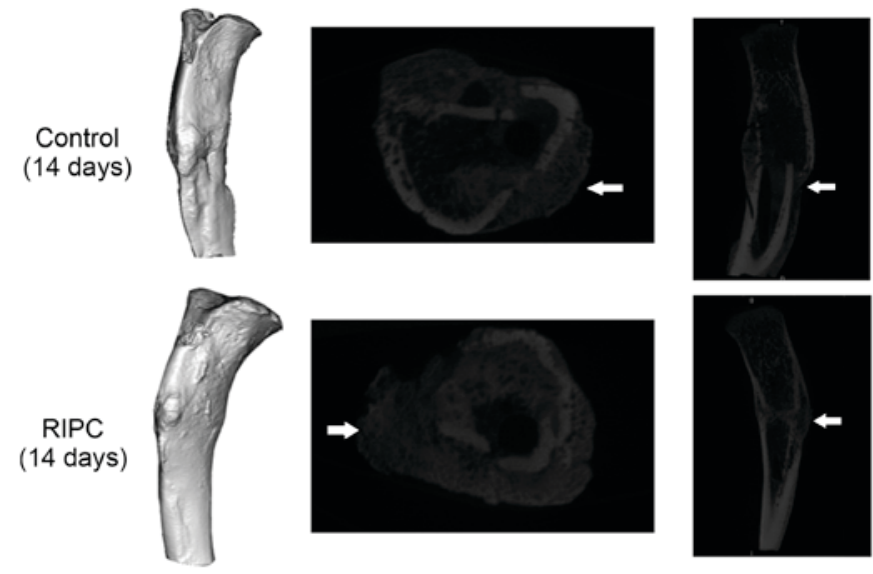

Figure 2. Micro-computed tomography images of the fracture callus 14 days after fracture. Representative images of each group are presented. The arrows indicate the callus. RIPC, remote ischemic post-conditioning.

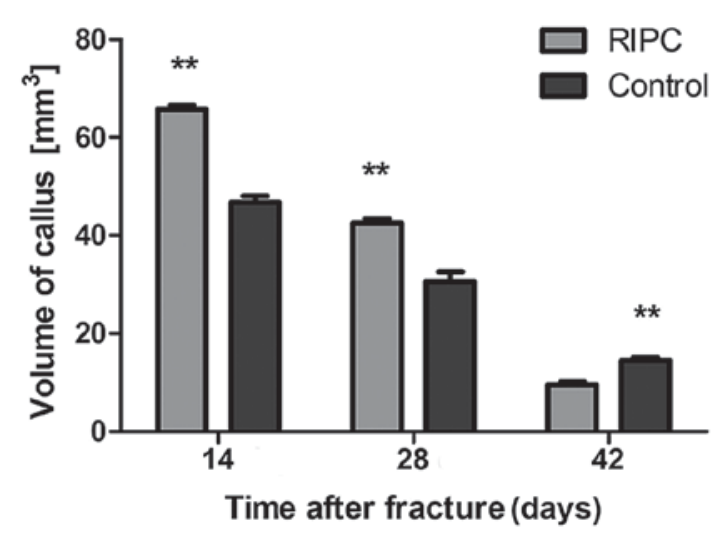

Figure 3. Callus volume obtained at 14, 28 and 42 days for each group. Data are expressed as the mean \pm standard deviation $(n=8) .{ }^{* *} \mathrm{P}<0.01$ vs. control group. RIPC, remote ischemic post-conditioning.

effect of RIPC on fracture healing is partially mediated via the HIF-1 $\alpha$ signaling pathway.

IHC analysis. Runx 2 is considered to be an osteoblast-specific transcriptional factor and is involved in chondrocyte maturation and osteoblast differentiation $(27,28)$. Osteoblast-specific gene expression, including ALP and OCN, are important markers (29). Based on the above data, the expression of Runx2, ALP and OCN was analyzed by IHC in bone tissues 42 days after the fracture. Increased expression of Runx2, ALP and OCN was observed in the RIPC compared with the control group (Fig. 7). These data further suggested that RIPC induces fracture healing through activation of HIF-1 $\alpha$ and its target genes.

Biomechanical assessment. To further assess the functional features of fracture healing, the influence of RIPC on the mechanical properties of the tibias of rats was investigated. The dimensions of all testing specimens were performed according to the guidelines of the American Society for Testing and Materials for the uniaxial strength testing (26). The RIPC group was significantly stronger than the control group $(\mathrm{P}<0.05$; Table I). The force required to break the bone

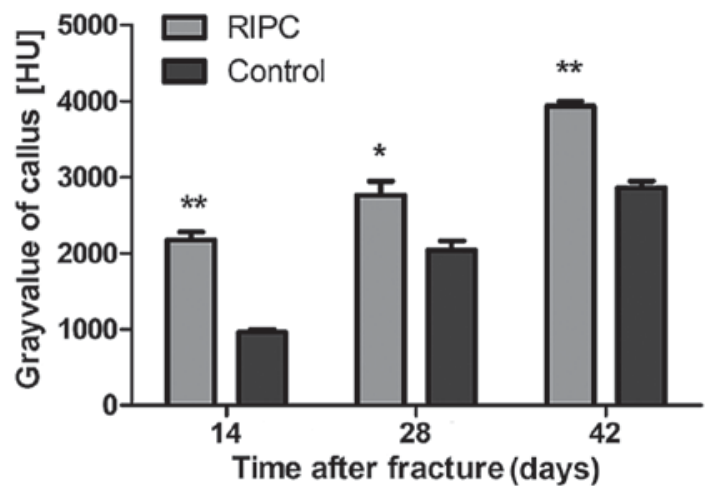

Figure 4. Gray value obtained at 14, 28 and 42 days for each group. Data are expressed as the mean \pm standard deviation $(\mathrm{n}=8)$. ${ }^{*} \mathrm{P}<0.05$ and ${ }^{* * *} \mathrm{P}<0.01$ vs. control group. RIPC, remote ischemic post-conditioning.

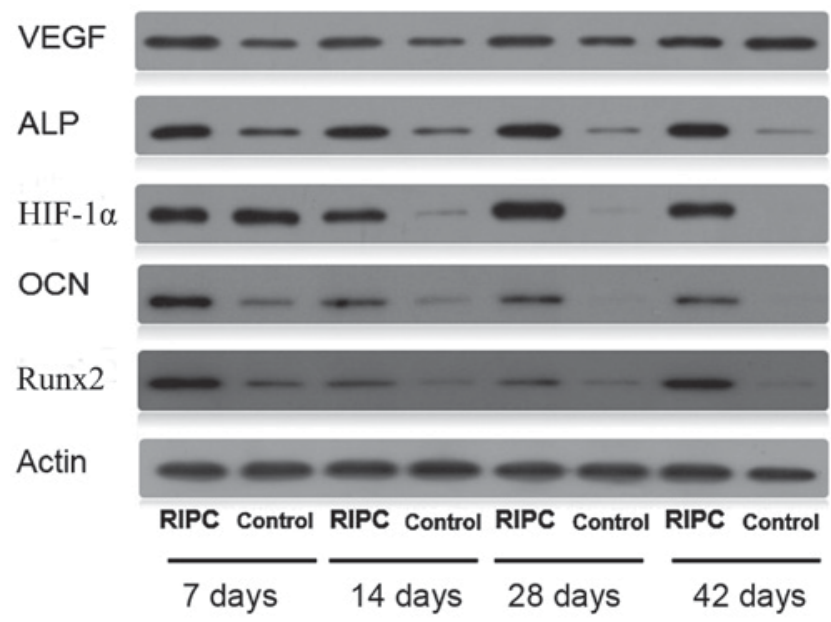

Figure 5. Western blot analysis of bone lysates using HIF-1 $\alpha$, VEGF, Runx2, ALP, OCN and $\beta$-actin antibodies. RIPC, remote ischemic post-conditioning; HIF-1 $\alpha$, hypoxia-inducible factor-1 $\alpha$; VEGF, vascular endothelial growth factor; Runx2, Runt-related transcription factor 2; ALP, alkaline phosphatase; OCN, osteocalcin.

and structural stiffness of the fractured tibia was 49.1 and $47.9 \%$ greater, respectively, compared with the control group at 42 days $(\mathrm{P}<0.01)$.

\section{Discussion}

Normal fracture healing is a complex process involving cellular recruitment, specific gene expression and synthesis of compounds that regenerate native tissue to restore the mechanical integrity and function of damaged bone (30). There are numerous aspects of fracture healing, including biological, nutritional, physical and genetic factors. A previous study demonstrated that hypoxia may promote fracture healing and that the osteoblast-specific transcriptional factor Runx2 and the osteoblast-specific genes ALP and OCN are increased (8). These findings provide a potential strategy to induce bone tissue regeneration.

Remote ischemic conditioning (RIC) has been demonstrated to induce intramyocardial cardioprotection across different coronary artery areas (15). However, it has since been indicated that the heart may be protected by an RIC 

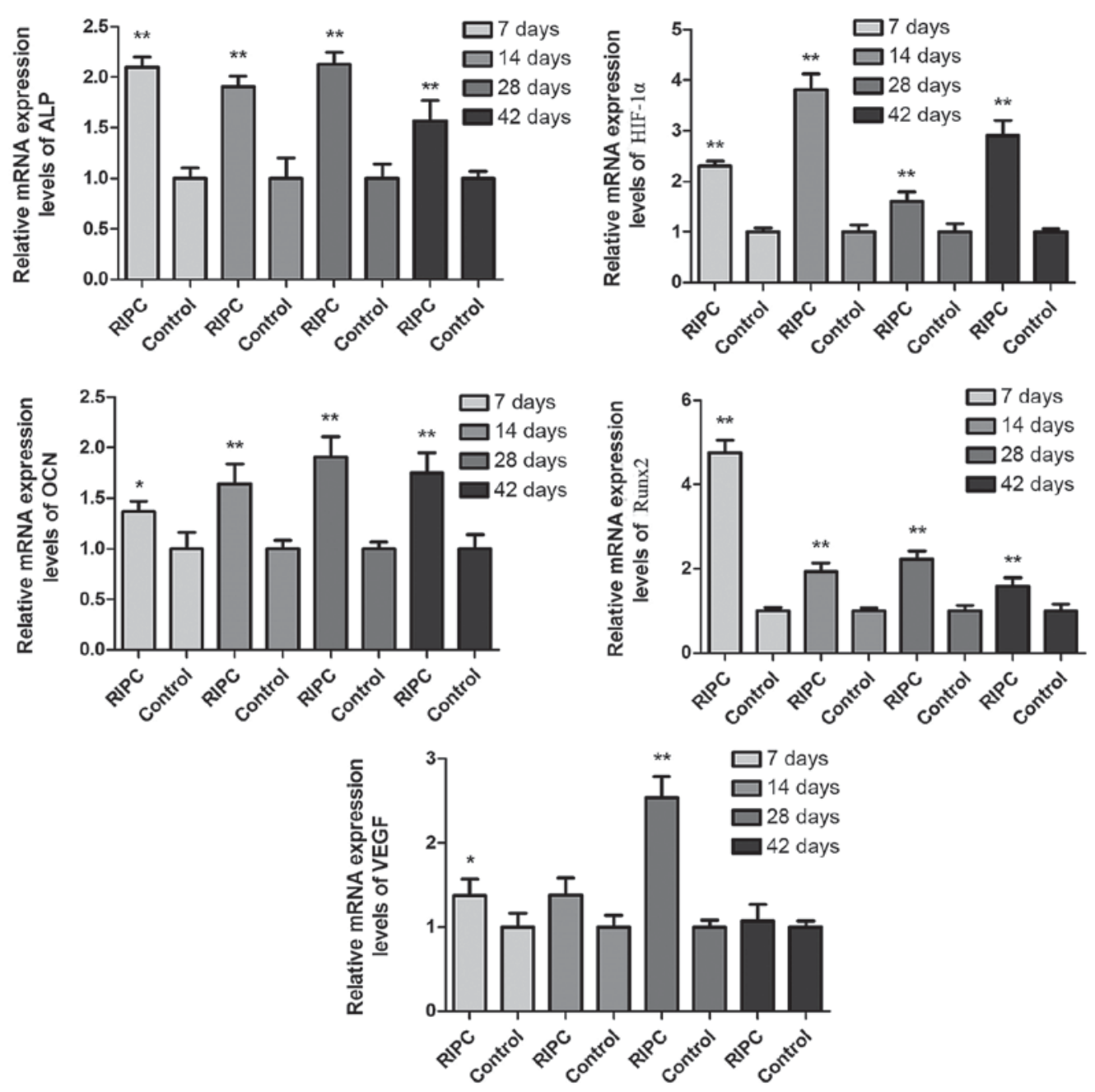

Figure 6. Reverse transcription-quantitative polymerase chain reaction analysis of relative mRNA expression levels of ALP, HIF-1 $\alpha$, OCN, Runx2 and VEGF. Data are expressed as the mean \pm standard deviation $(n=8)$. ${ }^{*}<<0.05$ and ${ }^{* *} \mathrm{P}<0.01$ vs. control group. RIPC, remote ischemic post-conditioning; ALP, alkaline phosphatase; HIF-1 $\alpha$, hypoxia-inducible factor-1 $\alpha$; OCN, osteocalcin; Runx2, Runt-related transcription factor 2; VEGF, vascular endothelial growth factor.

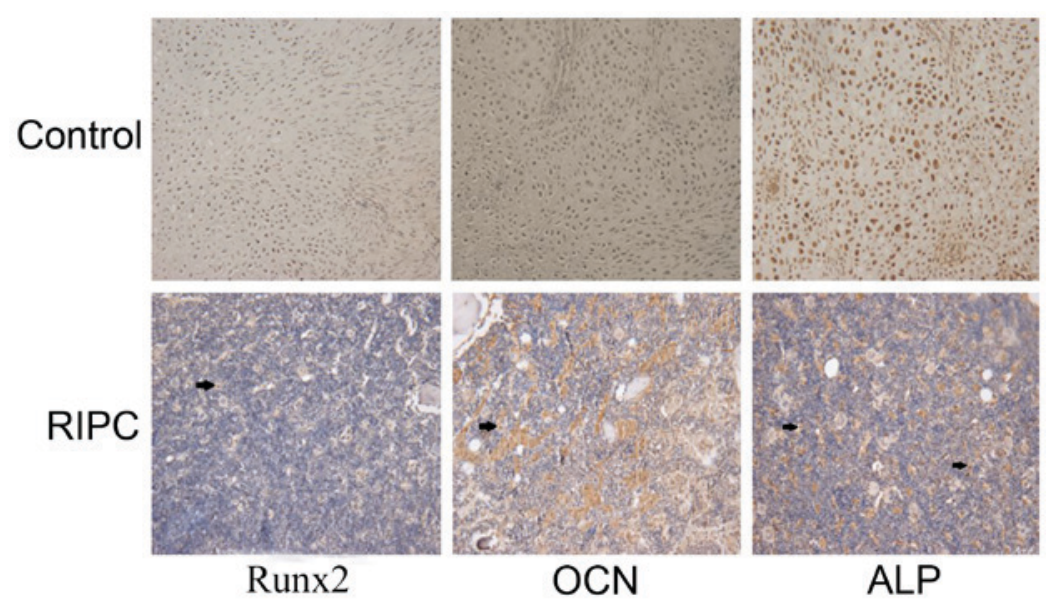

Figure 7. Representative images of immunohistochemical staining of Runx2, OCN and ALP in bone tissues 42 days after fracture. RIPC, remote ischemic post-conditioning; Runx2, Runt-related transcription factor 2; OCN, osteocalcin; ALP, alkaline phosphatase.

stimulus applied to an organ remote from the heart, including the kidney, small intestine, brain, liver, pancreas and lung (31). The non-invasive hind limb ischemia model was reported by Oxman et al (32), and was demonstrated to reduce reperfusion arrhythmias in a rat heart following a sustained ischemic insult. Numerous studies have since confirmed the use of the lower limb for RIC due to its ease of access $(11,33-35)$. This method has been revealed to be effective and 
Table I. Biomechanical testing evaluated by three-point bending.

\begin{tabular}{|c|c|c|c|c|}
\hline \multirow[b]{2}{*}{ Parameter } & \multicolumn{2}{|c|}{ Control group (day) } & \multicolumn{2}{|c|}{ RIPC group (day) } \\
\hline & 28 & 42 & 28 & 42 \\
\hline Maximum force $(\mathrm{N})$ & $72.4 \pm 2.9$ & $121.6 \pm 7.1$ & $82.9 \pm 5.4^{\mathrm{a}}$ & $181.3 \pm 12.7^{\mathrm{b}}$ \\
\hline Stiffness $(\mathrm{N} / \mathrm{mm})$ & $201.1 \pm 12.1$ & $310.5 \pm 21.3$ & $242.1 \pm 12.1^{\mathrm{a}}$ & $459.2 \pm 19.7^{\mathrm{b}}$ \\
\hline Work to fracture (N-mm) & $19.9 \pm 1.1$ & $35.2 \pm 3.2$ & $21.9 \pm 2.5$ & $51.2 \pm 4.2^{\mathrm{a}}$ \\
\hline
\end{tabular}

Data are expressed as the mean \pm standard deviation. Each time point contained 3 samples per group (total 8 rats per group). ${ }^{a} \mathrm{P}<0.05$ and ${ }^{\mathrm{b}} \mathrm{P}<0.01$ vs. control group. RIPC, remote ischemic post-conditioning.

reproducible in reducing injury of other organs in animals and humans (36).

Growing evidence indicated that HIF-1 $\alpha$ may be involved in the early phase of IPC, within min of the IPC stimulus (37). In the present study, upregulated expression of HIF-1 $\alpha$ was detected in bone tissue. HIF-1 $\alpha$ interacts with the core DNA sequence of 5'-[AG]CGTG-3' at the hypoxia response element target gene promoters to upregulate numerous hypoxia-sensitive genes, including VEGF (38). The present study revealed that RIPC has positive effects on the expression of Runx2, which is considered to be the primary controlling transcription factor in osteoblast differentiation (39); ALP is another essential factor. Runx2 and ALP are required for osteogenesisin vivo $(40,41)$. OCN is an important marker of mature osteoblasts. The protein serves a role in the differentiation of osteoblast progenitor cells, with significant upregulation observed in matrix synthesis and mineralization $(42,43)$. Micro-CT in the present study demonstrated that the volume of callus in the RIPC group was significantly larger compared with the control group during the callus formation stage (at 14 days), and the gray value, which represents bone mineral density, was additionally increased in the RIPC group. At 42 days, the gray value of the RIPC group approached healthy cortical bone (gray-value $=4120 \pm 112 \mathrm{HU}$ ). The biomechanical properties of the healing construct may be attributed to density and quantity of tissue; biomechanical analysis revealed that RIPC significantly increased the maximum load, stiffness and energy absorption. Taken together, these results suggested that RIPC enhanced the osteoblast proliferation rate and recovered bone nodular mineralization.

Although various studies have demonstrated that remote conditioning shares similar mechanistic signaling pathways with local conditioning $(44,45)$, evidence indicates that the IPC and RIPC signaling pathways are not identical (46). The following three potential underlying mechanisms of RIPC have been proposed: i) Humoral factors released in the pre-conditioned organ are transported via the blood circulation to protect the target organ (47); ii) neurogenic transmission with involvement of muscle afferents and the autonomic nervous system (47); and iii) immunomodulation (48). Several studies have suggested that the underlying protective mechanisms of RIPC are associated with its ability to attenuate the production of free radicals, promote the cell survival pathway, modulate the immune system and inhibit the apoptotic cell signaling pathways (49-51). However, further research is required to determine the exact mechanisms underlying RIPC.

In recent years, RIPC has emerged as an effective strategy for reducing myocardial ischemia/reperfusion injury. The ability to use transient limb ischemia as a remote conditioning stimulus has facilitated progression from the bench to the bedside and has applications in various clinical settings (11). The present study supports the use of RIPC as a valid strategy to enhance fracture healing. These experimental observations may be translated into the clinical setting. In addition, the present study adds information regarding the mechanisms of RIPC.

\section{Acknowledgements}

The present study was supported by the National Natural Science Foundation of China (grant. no. 81541135).

\section{References}

1. Marsell R and Einhorn TA: The biology of fracture healing. Injury 42: 551-555, 2011.

2. Giannoudis PV, Jones E and Einhorn TA: Fracture healing and bone repair. Injury 42: 549-550, 2011.

3. Bishop JA, Palanca AA, Bellino MJ and Lowenberg DW: Assessment of compromised fracture healing. J Am Acad Orthop Surg 20: 273-282, 2012.

4. Wan C, Gilbert SR, Wang Y, Cao X, Shen X, Ramaswamy G, Jacobsen KA, Alaql ZS, Eberhardt AW, Gerstenfeld LC, et al: Activation of the hypoxia-inducible factor-1alpha pathway accelerates bone regeneration. Proc Natl Acad Sci USA 105: 686-691, 2008.

5. Raheja LF, Genetos DC and Yellowley CE: Hypoxic osteocytes recruit human MSCs through an OPN/CD44-mediated pathway. Biochem Biophys Res Commun 366: 1061-1066, 2008.

6. Street J, Bao M, deGuzman L, Bunting S, Peale FV Jr, Ferrara N, Steinmetz H, Hoeffel J, Cleland JL, Daugherty A, et al: Vascular endothelial growth factor stimulates bone repair by promoting angiogenesis and bone turnover. Proc Natl Acad Sci USA 99: 9656-9661, 2002.

7. Loboda A, Jazwa A, Wegiel B, Jozkowicz A and Dulak J: Heme oxygenase-1-dependent and -independent regulation of angiogenic genes expression: Effect of cobalt protoporphyrin and cobalt chloride on VEGF and IL-8 synthesis in human microvascular endothelial cells. Cell Mol Biol (Noisy-le-grand) 51: 347-355, 2005.

8. Huang J, Liu L, Feng M, An S, Zhou M, Li Z, Qi J and Shen H: Effect of $\mathrm{CoCl} 2$ on fracture repair in a rat model of bone fracture. Mol Med Rep 12: 5951-5956, 2015.

9. Saeedi SS, Karami S, Karami B and Shokrzadeh M: Toxic effects of cobalt chloride on hematological factors of common carp (Cyprinus carpio). Biol Trace Elem Res 132: 144-152, 2009. 
10. Baik SW, Park BS, Kim YH, Kim YD, Kim CH, Yoon JY and Yoon JU: Effects of remifentanil preconditioning on osteoblasts under hypoxia-reoxygenation condition. Int J Med Sci 12: 583-589, 2015.

11. Kalakech H, Tamareille S, Pons S, Godin-Ribuot D, Carmeliet P, Furber A, Martin V, Berdeaux A, Ghaleh B and Prunier F: Role of hypoxia inducible factor- $1 \alpha$ in remote limb ischemic preconditioning. J Mol Cell Cardiol 65: 98-104, 2013.

12. Stefanini MO, Wu FT, Mac Gabhann F and Popel AS: A compartment model of VEGF distribution in blood, healthy and diseased tissues. BMC Syst Biol 2: 77, 2008.

13. Szijártó A, Czigány Z, Turóczi Z and Harsányi L: Remote ischemic perconditioning-a simple, low-risk method to decrease ischemic reperfusion injury: Models, protocols and mechanistic background. A review. J Surg Res 178: 797-806, 2012.

14. Zhao ZQ, Corvera JS, Halkos ME, Kerendi F, Wang NP, Guyton RA and Vinten-Johansen J: Inhibition of myocardial injury by ischemic postconditioning during reperfusion: Comparison with ischemic preconditioning. Am J Physiol Heart Circ Physiol 285: H579-H588, 2003.

15. Przyklenk K, Bauer B, Ovize M, Kloner RA and Whittaker P Regional ischemic 'preconditioning' protects remote virgin myocardium from subsequent sustained coronary occlusion. Circulation 87: 893-899, 1993

16. Ren C, Yan Z, Wei D, Gao X, Chen X and Zhao H: Limb remote ischemic postconditioning protects against focal ischemia in rats. Brain Res 1288: 88-94, 2009.

17. Xiong J, Liao X, Xue FS, Yuan YJ, Wang Q and Liu JH: Remote ischemia conditioning-an endogenous cardioprotective strategy from outside the heart. Chin Med J (Engl) 124: 2209-2215, 2011.

18. Leosco D, Rengo G, Iaccarino G, Sanzari E, Golino L, De Lisa G, Zincarelli C, Fortunato F, Ciccarelli M, Cimini V, et al: Prior exercise improves age-dependent vascular endothelial growth factor downregulation and angiogenesis responses to hind-limb ischemia in old rats. J Gerontol A Biol Sci Med Sci 62: 471-480, 2007.

19. Petersen W, Wildemann B, Pufe T, Raschke $M$ and Schmidmaier G: The angiogenic peptide pleiotrophin (PTN/HB-GAM) is expressed in fracture healing: An immunohistochemical study in rats. Arch Orthop Trauma Surg 124: 603-607, 2004.

20. Ren C, Wang P, Wang B, Li N, Li W, Zhang C, Jin K and Ji X: Limb remote ischemic per-conditioning in combination with post-conditioning reduces brain damage and promotes neuroglobin expression in the rat brain after ischemic stroke. Restor Neurol Neurosci 33: 369-379, 2015.

21. Komrakova M, Weidemann A, Dullin C, Ebert J, Tezval M, Stuermer KM and Sehmisch S: The impact of strontium ranelate on metaphyseal bone healing in ovariectomized rats. Calcif Tissue Int 97: 391-401, 2015.

22. Bouxsein ML, Boyd SK, Christiansen BA, Guldberg RE, Jepsen KJ and Muller R: Guidelines for assessment of bone microstructure in rodents using micro-computed tomography. J Bone Miner Res 25: 1468-1486, 2010

23. Zhou M, Shen D, Head JE, Chew EY, Chévez-Barrios P, Green WR and Chan CC: Ocular clusterin expression in von Hippel-Lindau disease. Mol Vis 13: 2129-2136, 2007.

24. Livak KJ and Schmittgen TD: Analysis of relative gene expression data using real-time quantitative PCR and the 2(-Delta Delta C(T)) Method. Methods 25: 402-408, 2001.

25. Gerstenfeld LC, Wronski TJ, Hollinger JO and Einhorn TA: Application of histomorphometric methods to the study of bone repair. J Bone Miner Res 20: 1715-1722, 2005.

26. Gutierrez GE, Edwards JR, Garrett IR, Nyman JS, McCluskey B Rossini G, Flores A, Neidre DB and Mundy GR: Transdermal lovastatin enhances fracture repair in rats. J Bone Miner Res 23: $1722-1730,2008$

27. Inada M, Yasui T, Nomura S, Miyake S, Deguchi K, Himeno M, Sato M, Yamagiwa H, Kimura T, Yasui N, et al: Maturational disturbance of chondrocytes in Cbfa1-deficient mice. Dev Dyn 214: 279-290, 1999.

28. Lian JB, Javed A, Zaidi SK, Lengner C, Montecino M, van Wijnen AJ, Stein JL and Stein GS: Regulatory controls for osteoblast growth and differentiation: Role of Runx/Cbfa/AML factors. Crit Rev Eukaryot Gene Expr 14: 1-41, 2004.

29. Mimori K, Komaki M, Iwasaki K and Ishikawa I: Extracellular signal-regulated kinase $1 / 2$ is involved in ascorbic acid-induced osteoblastic differentiation in periodontal ligament cells. J Periodontol 78: 328-334, 2007.
30. Komatsu DE and Warden SJ: The control of fracture healing and its therapeutic targeting: Improving upon nature. J Cell Biochem 109: 302-311, 2010.

31. Lim SY and Hausenloy DJ: Remote ischemic conditioning: From bench to bedside. Front Physiol 3: 27, 2012

32. Oxman T, Arad M, Klein R, Avazov N and Rabinowitz B: Limb ischemia preconditions the heart against reperfusion tachyarrhythmia. Am J Physiol 273: H1707-H1712, 1997.

33. Jeanneteau J, Hibert P, Martinez MC, Tual-Chalot S, Tamareille S, Furber A, Andriantsitohaina R and Prunier F: Microparticle release in remote ischemic conditioning mechanism. Am J Physiol Heart Circ Physiol 303: H871-H877, 2012.

34. Karakoyun R, Koksoy C, Yilmaz TU, Altun H, Banli O, Albayrak A, Alper M and Sener Z: The angiogenic effects of ischemic conditioning in experimental critical limb ischemia. Eur J Vasc Endovasc Surg 47: 172-179, 2014.

35. Zhang Y, Liu X, Yan F, Min L, Ji X and Luo Y: Protective effects of remote ischemic preconditioning in rat hindlimb on ischemiareperfusion injury. Neural Regen Res 7: 583-587, 2012.

36. Tapuria N, Kumar Y, Habib MM, Abu Amara M, Seifalian AM and Davidson BR: Remote ischemic preconditioning: A novel protective method from ischemia reperfusion injury-a review. J Surg Res 150: 304-330, 2008

37. Shi W and Vinten-Johansen J: Endogenous cardioprotection by ischaemic postconditioning and remote conditioning. Cardiovase Res 94: 206-216, 2012

38. Formenti F, Constantin-Teodosiu D, Emmanuel Y, Cheeseman J, Dorrington KL, Edwards LM, Humphreys SM, Lappin TR, McMullin MF, McNamara CJ, et al: Regulation of human metabolism by hypoxia-inducible factor. Proc Natl Acad Sci USA 107: 12722-12727, 2010

39. Komori T: Regulation of osteoblast differentiation by transcription factors. J Cell Biochem 99: 1233-1239, 2006.

40. Banerjee C, Javed A, Choi JY, Green J, Rosen V, van Wijnen AJ, Stein JL, Lian JB and Stein GS: Differential regulation of the two principal Runx $2 / \mathrm{Cbfa} 1 \mathrm{n}$-terminal isoforms in response to bone morphogenetic protein-2 during development of the osteoblast phenotype. Endocrinology 142: 4026-4039, 2001

41. Gao J, Fu S, Zeng Z, Li F, Niu Q, Jing D and Feng X: Cyclic stretch promotes osteogenesis-related gene expression in osteoblast-like cells through a cofilin-associated mechanism. Mol Med Rep 14: 218-224, 2016.

42. Karsenty G and Wagner EF: Reaching a genetic and molecular understanding of skeletal development. Dev Cell 2: 389-406, 2002.

43. Murshed M, Harmey D, Millán JL, McKee MD and Karsenty G: Unique coexpression in osteoblasts of broadly expressed genes accounts for the spatial restriction of ECM mineralization to bone. Genes Dev 19: 1093-1104, 2005.

44. Hausenloy DJ and Yellon DM: Remote ischaemic preconditioning: Underlying mechanisms and clinical application. Cardiovasc Res 79: 377-386, 2008

45. Selzner N, Boehnert M and Selzner M: Preconditioning, postconditioning, and remote conditioning in solid organ transplantation: Basic mechanisms and translational applications. Transplant Rev (Orlando) 26: 115-124, 2012.

46. Grall S, Prunier-Mirebeau D, Tamareille S, Mateus V, Lamon D, Furber A and Prunier F: Endoplasmic reticulum stress pathway involvement in local and remote myocardial ischemic conditioning. Shock 39: 433-439, 2013

47. Kanoria S, Jalan R, Seifalian AM, Williams R and Davidson BR: Protocols and mechanisms for remote ischemic preconditioning: A novel method for reducing ischemia reperfusion injury. Transplantation 84: 445-458, 2007.

48. Zhao $\mathrm{H}$ : The protective effects of ischemic postconditioning against stroke: From rapid to delayed and remote postconditioning. Open Drug Discov J 5: 138-147, 2011.

49. Hoda MN, Fagan SC, Khan MB, Vaibhav K, Chaudhary A, Wang P, Dhandapani KM, Waller JL and Hess DC: A 2 x 2 factorial design for the combination therapy of minocycline and remote ischemic perconditioning: Efficacy in a preclinical trial in murine thromboembolic stroke model. Exp Transl Stroke Med 6: 10, 2014.

50. Wang JY, Shen J, Gao Q, Ye ZG, Yang SY, Liang HW, Bruce IC Luo BY and Xia Q: Ischemic postconditioning protects against global cerebral ischemia/reperfusion-induced injury in rats. Stroke 39: 983-990, 2008.

51. Xing B, Chen H, Zhang M, Zhao D, Jiang R, Liu X and Zhang S: Ischemic postconditioning inhibits apoptosis after focal cerebral ischemia/reperfusion injury in the rat. Stroke 39: 2362-2369, 2008. 